\title{
Association of chronic diseases and lifestyle factors with suicidal ideation among adults aged 18-69 years in Eswatini: evidence from a population-based survey
}

\author{
Mfundi President Sebenele Motsa ${ }^{1}\left[0\right.$, Hung-Yi Chiou $^{2,3}(0)$ and Yi-Hua Chen ${ }^{2 *}$
}

\begin{abstract}
Background: How chronic diseases and lifestyle affect suicidal ideation in the sub-Saharan region remains unclear. We investigated the association of chronic diseases and lifestyle with suicidal ideation in the past year and the potential modifying role of sociodemographic status on this association. The findings can guide suicide prevention interventions.
\end{abstract}

Methods: We analyzed 3026 respondents from the World Health Organization STEPwise approach to noncommunicable disease risk factor surveillance conducted in Eswatini in 2014. The outcome was past-year suicidal ideation, and the main predictors were chronic diseases and lifestyle. Multiple logistic regression was used to estimate predictors, and subgroup analysis was performed to assess effect modification.

Results: The prevalence of past-year suicidal ideation was 9.9\%. After adjustment for covariates, including sex, marital status, employment status, and education level, individuals aged 18-30 years (adjusted odds ratio [aOR]: 2.27, 95\% confidence interval [CI]: 1.22-4.22) were more likely to have had past-year suicidal ideation than those aged 45-69 years. After adjustment for covariates among employed individuals, having high blood pressure (aOR: 3.38, 95\% Cl: 1.54-7.40), not exercising (aOR: 2.65, 95\% Cl: 1.09-6.39), drinking alcohol (aOR: 2.40, 95\% Cl: 1.14-5.05), being aged 18-30 years (aOR: 3.50, 95\% Cl: 1.01-12.1), and being exposed to threats (aOR: $2.37,95 \%$ Cl: 1.01-5.53) were significantly associated with past-year suicidal ideation.

Conclusions: Among currently employed individuals, having high blood pressure, not exercising, and drinking alcohol were associated with past-year suicidal ideation. The findings highlight the importance of developing and strengthening systems for early identification of suicidal ideation risk.

Keywords: Suicidal ideation, Chronic disease, Lifestyle, Exercise

*Correspondence: yichen@tmu.edu.tw

${ }^{2}$ School of Public Health, College of Public Health, Taipei Medical University, 250 Wuxing St., Taipei City 110, Taiwan

Full list of author information is available at the end of the article

\section{Introduction}

Suicide is a major global health concern and a substantial contributor to mortality worldwide; yet, it is preventable [1]. One person is estimated to commit suicide every $40 \mathrm{~s}$, and approximately $79 \%$ of these deaths occur in developing countries [2]. In general, not all people with suicidal ideation will attempt suicide, but on the continuum of suicidal behavior, it is a first step [3]. The number 
of individuals who engage in suicidal behaviors is worrisome [2], and this problem could be addressed through early identification of suicidal ideation [4]. Suicidal ideation entails thinking about, considering, and planning suicide [4-6]. Moreover, suicidal ideation is the first step on the suicidal behavior continuum, and knowledge regarding the transition from ideation to action helps form prevention strategies [7].

The estimated global lifetime prevalence of suicidal ideation is 9.2\% [7], and for low- and middle-income countries (LMICs), the lifetime prevalence of suicidal ideation is higher (10.3\%) [8]. Although the World Health Organization (WHO) has recommended a mental health gap action program to reduce suicides in member states [9], the magnitude of the problem remains high; estimates indicate that suicides account for $1.42 \%(1.33-1.46 \%)$ of overall deaths per 100,000 people globally, with the highest proportion in Europe (1.53\%; 1.48-1.58\%); in Africa, it is $0.87 \%(0.79-0.96 \%)$ [1]. Most cross-national studies on suicidal ideation focused on the adult population have investigated participants from developed countries [6, 10]; few have involved the sub-Saharan region (SSA) [11].

Many factors are associated with suicidal ideation, and some variations have been observed between regions and countries with respect to sociodemographic variables, comorbidities, and lifestyle factors [12-14]. A meta-analysis of studies from European countries suggested that the number of chronic health conditions is associated with suicidal ideation among adults [10]. Additionally, evidence from developed countries has suggested that physical health problems, including high blood pressure (HBP) [15-17] and cardiovascular disease (CVD) [18], are positively associated with suicidal ideation. Similarly, literature from developing countries has revealed that physical illness $[11,19,20]$ and CVD [20] are associated with suicidal ideation.

Studies from developing countries have reported an association between lifestyle factors (smoking, drinking alcohol, and exercise) and suicidal ideation among adults [21, 22], as have studies from developed countries [23]. A meta-analysis indicated that physical exercise is negatively associated with suicidal ideation [24]. A South African case-control study reported that alcohol increases the chances of hospitalization from suicidal behavior [25]; however, this study focused on suicide attempts and not ideation.

Suicide is among the leading causes of mortality in Eswatini, with an estimated age-standardized rate of 16.7 per 100,000 persons in 2016 [26]. A study conducted in Eswatini among school-going adolescents revealed that age, sex, food insecurity, and sexual behavior were associated with suicidal behavior [27]. However, population-based factors that influence the adult population are unclear. Another study from Eswatini involving 15-69-year-old adults indicated that childhood and adult sexual abuse and threats were associated with suicidal ideation [28]. However, this study had the following limitations: it included adolescents in the study sample, which may have inflated the suicidal ideation risk because if ideation begins during adolescence, it may persist throughout adulthood if left unaddressed [29]; it defined the outcome as a combination of suicidal thoughts, plans, and recent suicide attempts, which is nonspecific; and it focused on abuse-related factors rather than the effects of chronic diseases and lifestyle factors.

Although some studies have addressed the influence of chronic diseases and lifestyle factors on suicidal ideation, few have focused on Eswatini. The mortality rates attributable to noncommunicable diseases in Eswatini are high, estimated at 37\% in 2016 [30]. Therefore, investigating the association of chronic diseases and lifestyle with suicidal ideation is crucial for improving intervention strategies against suicidal ideation. In addition, examining how socioeconomic status (SES) is a potential effect modifier on suicidal ideation is crucial to identify highrisk groups. Studies have considered suicidal behavior in general, but few have focused on past-year suicidal ideation. To address this gap in the literature, we investigated, first, the association of chronic diseases and lifestyle with past-year suicidal ideation and, second, the potential modifying role of SES in this association.

\section{Methods}

\section{Study design and data source}

This study involved the secondary analysis of data obtained from the WHO STEPwise approach to surveillance (STEPS) conducted in Eswatini in 2014 [31], which was designed to collect data on noncommunicable disease risk factors at the population level among adults aged 15-69 years. The selection procedure for the survey is detailed elsewhere [32]. Briefly, the STEPS employed a multistage cluster sampling design. In total, 216 primary sampling units (PSUs) were selected using probability-proportionate-to-size sampling, and approximately 20 households were systematically sampled from the PSUs to form secondary sampling units. A Kish sampling method was used to identify an eligible person from each household. Data were collected for 32 days from November to December 2014. Participants were adult men and women aged 15-69 years from all four regions of Eswatini.

The overall sample size of STEPS was 3534; however, for this analysis, we excluded 275 individuals aged $<18$ years and 233 individuals who did not answer suicidal ideation questions. Our final sample had 3026 participants aged 18-69 years who responded to questions on 
suicide, with the answers used to ascertain whether they had suicidal thoughts. We focused on this age group because studies have examined factors associated with suicidal behavior among adolescents and adults but have not evaluated adult-only factors, which may be different $[27,28]$. Furthermore, we examined differences in sociodemographics (SES) and the key factors of chronic diseases (HBP and CVD) and lifestyle (lifetime alcohol use, currently smoking, and exercise) between those who responded $(\mathrm{n}=3026)$ and those who did not respond $(\mathrm{n}=233)$ to questions on past-year suicidal ideation. No significant differences were noted between the two groups.

\section{Outcome variable}

The outcome of interest in this analysis was past-year suicidal ideation. In this study, past-year suicidal ideation was defined as a respondent's feelings or thoughts regarding killing themselves. It was determined based on the following item in STEPS: "During the past 12 months, have you seriously considered attempting suicide?" The response options were "yes" and "no," and we recorded past-year suicidal ideation yes and suicidal ideation no as 1 or 0 , respectively.

\section{Independent variables}

The main independent variables in this study were chronic diseases (i.e., HBP and CVD) and lifestyle factors (i.e., exercise, lifetime alcohol use, and currently smoking). HBP was assessed using the item "Have you ever been told by a doctor or other health worker that you have raised blood pressure or hypertension?" CVD was assessed using the item "Have you ever had a heart attack or chest pain from heart disease (angina) or stroke (cerebrovascular accident or incident)?" Exercise was assessed using the item "Do you do any moderate-intensity sports, fitness activities, or recreational (leisure) activities that cause a small increase in breathing or heart rate such as brisk walking, cycling, swimming, and volleyball for at least 10 min continually?" Lifetime alcohol use was assessed using the item "Have you ever consumed any alcohol such as beer, wine, spirits, or other local variants?" Currently smoking was assessed using the item "Do you currently smoke any tobacco products, such as cigarettes, cigars, and pipes?"

\section{Covariates}

Abuse-related factors were considered covariates in this study because of their effects on our main variables [33]. Childhood sexual abuse was assessed by asking, "Looking back on your childhood, did an adult or anyone at least 5 years older than you ever touch you sexually or try to make you touch them sexually or force you to have sex?" Adult sexual abuse was assessed by asking, "Since your 18th birthday, have you ever experienced a sex act involving vaginal, oral, or anal penetration against your will?" Threat was determined by asking, "In the past 12 months, have you been frightened for your safety or that of your family because of the anger or threats of another person(s)?" Family history of a suicide attempt was assessed by asking, "Has anyone in your close family (parent, sibling, or children) ever attempted suicide?"

\section{Potential effect modifiers}

Using the literature $[6,34,35]$ and information of the Eswatini STEPS [32], we examined sociodemographic factors as potential effect modifiers. The variables were age (18-30, 31-45, and 46-69 years), sex (male and female), marital status (married, never married, and separated/divorced), educational level (primary and lower, secondary or lower, high school and higher), employment status (currently employed and currently unemployed), and residence (rural and urban).

\section{Statistical analysis}

Stata version (2017): Release 15 (StataCorp LP, College Station, TX, USA) was used for the analyses. We applied weights by using the svy command to account for the complex STEPS design and for clustering, stratification, and nonresponses. We assessed the prevalence of pastyear suicidal ideation for the entire study population. Variables are presented in terms of their frequency and percentage. Furthermore, we assessed bivariate associations between independent variables and past-year suicidal ideation by using the chi-square test. We assessed the unadjusted and adjusted associations of chronic diseases and lifestyle factors with past-year suicidal ideation by using logistic regression to estimate the odds of having past-year suicidal ideation. Our results are presented in terms of crude odds ratios and adjusted odds ratios (aORs) along with their 95\% confidence intervals (CIs). Statistical significance was indicated if $p<0.05$.

Interactions of chronic diseases and lifestyle factors with sociodemographic factors on past-year suicidal ideation were examined, and the interaction terms were considered significant if $p<0.1$ [36], in which case a subgroup analysis (stratification) was used for assessment. Sociodemographic characteristics were examined to assess potential modifying effects and were included in the model as a covariate for adjustment.

\section{Ethical considerations}

The survey complied with the standards governing the protection of human participants, and written informed consent was obtained from each respondent. The Swaziland Ethics Committee approved the initial STEPS, and 
the custodian of the data was notified about the intention to analyze the survey. Permission to analyze data was obtained from the WHO Non-communicable diseases (NCD) Microdata Repository, which serves as the custodian of publicly available data [31].

\section{Results \\ Distribution of participants by factors associated with past-year suicidal ideation}

The data of 3026 participants were analyzed. Table 1 presents their characteristics and the distribution of pastyear suicidal ideation according to independent variables. The overall prevalence of past-year suicidal ideation was 9.9\%. Chronic disease burden was high, with HBP and CVD at $25.7 \%$ and $13.1 \%$, respectively. Individuals with past-year suicidal ideation tended to have a history of CVD, have a history of lifetime alcohol use, be women, be currently unemployed, have a family history of suicide, and have experienced childhood sexual abuse, adult sexual abuse, or threats (all $p<0.05$ ).

\section{Factors associated with past-year suicidal ideation}

Table 2 presents the results of univariate, multivariable logistic, and stratified models that were used to examine factors associated with past-year suicidal ideation. After adjustment for sex, marital status, residence, current employment status, education level, HBP, CVD, currently smoking, lifetime alcohol use, childhood sexual abuse, adult sexual abuse, and threats, individuals aged 18-30 years were more likely to have past-year suicidal ideation $(\mathrm{aOR}=2.27,95 \% \mathrm{CI}=1.22-4.22)$ than those aged 46-69 years. Individuals with a family history of suicide were also more likely to have past-year suicidal ideation (aOR $=1.92,95 \% \mathrm{CI}=1.24-3.09)$ than those without. In addition, individuals who experienced childhood sexual abuse or threats were more likely to have past-year suicidal ideation $(\mathrm{aOR}=2.26,95 \% \mathrm{CI}=1.10-4.66$ and $\mathrm{aOR}$ $=1.88,95 \% \mathrm{CI}=1.15-3.06$, respectively) than those who did not. Chronic diseases and lifestyle factors were not associated with past-year suicidal ideation in the overall group.

\section{Subgroup analysis on the association of chronic disease and lifestyle factors with past-year suicidal ideation among individuals with different sociodemographic characteristics}

Our analysis revealed interactions between HBP and age $(p<0.03)$ and HBP and employment status $(p<0.002)$, which were significant enough to warrant a stratification analysis.

Further subgroup analysis (Tables 2 and 3) revealed that among individuals aged $18-30$ years, those who were separated/divorced $(\mathrm{aOR}=2.83,95 \% \mathrm{CI}=1.01-7.92)$ and those who had experienced childhood sexual abuse $(\mathrm{aOR}=3.59,95 \% \mathrm{CI}=1.32-9.75)$ were more likely to have past-year suicidal ideation than their respective counterparts. Moreover, among individuals aged 31-45 years, $\mathrm{HBP}(\mathrm{aOR}=3.28,95 \% \mathrm{CI}=1.36-7.88)$ was significantly associated with past-year suicidal ideation. Additionally, among currently employed individuals, $\mathrm{HBP}(\mathrm{aOR}=3.38,95 \% \mathrm{CI}=1.54-7.40)$, no exercise (aOR $=2.65,95 \% \mathrm{CI}=1.09-6.39)$, lifetime alcohol use (aOR $=2.40,95 \% \mathrm{CI}=1.14-5.05), 18-30$ years of age $(\mathrm{aOR}=$ $3.50,95 \% \mathrm{CI}=1.01-12.1)$, and exposure to threats (aOR $=2.37,95 \% \mathrm{CI}=1.01-5.53)$ were significantly associated with past-year suicidal ideation. Furthermore, among currently unemployed individuals, family history of suicide $(\mathrm{aOR}=2.42,95 \% \mathrm{CI}=1.07-5.45)$, childhood sexual abuse $(\mathrm{aOR}=2.58,95 \% \mathrm{CI}=1.24-5.38)$, and adult sexual abuse $(\mathrm{aOR}=4.94,95 \% \mathrm{CI}=1.94-12.5)$ were significantly associated with past-year suicidal ideation.

\section{Discussion}

Our findings contribute to the body of evidence for SSA and Eswatini regarding the association of chronic disease and lifestyle factors with past-year suicidal ideation. We examined the modifying role of sociodemographic characteristics in the association of chronic diseases and lifestyle factors with past-year suicidal ideation in Eswatini and revealed that the magnitude of past-year suicidal ideation was moderately high (9.9\%) and somewhat comparable to the global average (9.2\%) [7] and prevalence in Ethiopia (9\%) [37], lower than that in South Africa (14.8\%) [38], and higher than that in Nigeria (7.28\%) [39]. The differences in suicidal ideation prevalence may possibly be explained by cultural influences and the varying survey instruments used across all studies.

We did not find any association of chronic diseases and lifestyle factors with past-year suicidal ideation, contrary to studies in developed [16,40] and developing [20,41] countries. Our findings differ from existing evidence for the SSA countries [40] but are consistent with the data for other LMICs [34]. The variation could be explained by cultural differences between countries.

We demonstrated the moderating role of age and current employment on the association of chronic disease and lifestyle factors with past-year suicidal ideation. First, HBP was associated with past-year suicidal ideation among adults aged 31-45, and second, HBP, lack of exercise, and lifetime alcohol use were associated with past-year suicidal ideation among currently employed individuals. Our findings underscore the importance of suicidal ideation intervention in people with chronic diseases and certain lifestyle behaviors, particularly among currently employed individuals, in the Eswatini population $[11,41]$. 
Table 1 Chronic diseases and lifestyle factors associated with suicidal ideation

\begin{tabular}{|c|c|c|c|c|}
\hline \multirow[t]{2}{*}{ Characteristics } & \multirow{2}{*}{$\begin{array}{l}\text { Total } \\
(\mathrm{N}=3026) \\
\mathrm{n}(\%)\end{array}$} & \multicolumn{2}{|l|}{ Suicidal Ideation } & \multirow[t]{2}{*}{$p$ value } \\
\hline & & $\begin{array}{l}\text { Yes } \\
\text { n (\%, weighted) }\end{array}$ & $\begin{array}{l}\text { No } \\
\mathrm{n} \text { (\%, weighted) }\end{array}$ & \\
\hline \multicolumn{5}{|l|}{ Chronic disease } \\
\hline High blood pressure & & & & 0.45 \\
\hline Yes & $582(25.7)$ & $63(28.7)$ & $519(25.4)$ & \\
\hline No & $1363(74.3)$ & $133(71.3)$ & $1230(74.6)$ & \\
\hline Cardiovascular disease & & & & $0.04^{*}$ \\
\hline Yes & $102(13.1)$ & $26(7.7)$ & $105(4.6)$ & \\
\hline No & $644(86.9)$ & $272(92.3)$ & $2623(95.4)$ & \\
\hline \multicolumn{5}{|l|}{ Lifestyle factors } \\
\hline Exercise & & & & 0.13 \\
\hline Yes & $516(21)$ & $44(16.6)$ & $472(21.5)$ & \\
\hline No & $2510(79)$ & $254(83.4)$ & $2256(78.5)$ & \\
\hline Currently smoking & & & & 0.13 \\
\hline Yes & $191(6.9)$ & $25(9.9)$ & $166(6.6)$ & \\
\hline No & 2835 (93.1) & $273(90.1)$ & $2562(93.4)$ & \\
\hline Lifetime alcohol use & & & & $0.04^{*}$ \\
\hline Yes & $789(28.8)$ & $98(35.3)$ & $691(28.0)$ & \\
\hline No & $2237(71.2)$ & $200(64.7)$ & $2037(72.0)$ & \\
\hline \multicolumn{5}{|l|}{ Demographics } \\
\hline Age (years) & & & & 0.25 \\
\hline $18-30$ & $1182(52.2)$ & $124(56.7)$ & $1058(51.7)$ & \\
\hline $31-45$ & $857(26.4)$ & $91(25.9)$ & $766(26.4)$ & \\
\hline $46-69$ & $987(21.4)$ & $83(17.4)$ & $904(21.9)$ & \\
\hline Sex & & & & $<0.001^{*}$ \\
\hline Women & $2010(55.7)$ & $227(68.7)$ & $1783(54.3)$ & \\
\hline Men & $1016(44.3)$ & $71(31.3)$ & $945(45.7)$ & \\
\hline Marital status & & & & 0.17 \\
\hline Married & $1236(51.8)$ & $110(49.4)$ & $1126(52.1)$ & \\
\hline Never married & $1383(38.6)$ & $135(36.9)$ & $1248(38.8)$ & \\
\hline Separated/divorce & $405(9.5)$ & $52(13.7)$ & $353(9.1)$ & \\
\hline Education level & & & & 0.94 \\
\hline Primary and lower & $971(24.6)$ & $100(23.8)$ & $871(24.6)$ & \\
\hline Secondary & $1260(44)$ & $136(45.2)$ & $1124(43.9)$ & \\
\hline High school and higher & $792(31.4)$ & $61(31)$ & $731(31.5)$ & \\
\hline Employment status & & & & $0.02^{*}$ \\
\hline Currently employed & $1229(39.7)$ & $99(31.7)$ & $1130(40.6)$ & \\
\hline Currently unemployed & $1715(60.3)$ & $190(68.3)$ & $1525(59.4)$ & \\
\hline Residence & & & & 0.90 \\
\hline Rural & $2205(71.3)$ & $218(71)$ & $1987(71.4)$ & \\
\hline Urban & $821(28.7)$ & $80(29)$ & $741(28.6)$ & \\
\hline Family history of suicide & & & & $0.002^{* *}$ \\
\hline Yes & $320(11.9)$ & $48(19.8)$ & $272(11.0)$ & \\
\hline No & $2704(88.1)$ & $248(80.2)$ & $2456(89.0)$ & \\
\hline Abuse factors & & & & $<0.001^{* *}$ \\
\hline \multicolumn{5}{|l|}{ Childhood sexual abuse } \\
\hline Yes & $175,519(5)$ & $40(14.4)$ & $135(4)$ & \\
\hline No & $2840(95)$ & $258(85.6)$ & $2582(96)$ & \\
\hline Adult sexual abuse & & & & $<0.001^{* *}$ \\
\hline Yes & $113(3.3)$ & $24(9.3)$ & $89(2.6)$ & \\
\hline No & $2898(96.7)$ & $274(90.7)$ & $2624(97.4)$ & \\
\hline Threats & & & & $<0.001^{* *}$ \\
\hline Yes & $388(13.9)$ & $75(25.5)$ & $313(12.6)$ & \\
\hline No & $2635(86.1)$ & $223(74.5)$ & $2412(87.4)$ & \\
\hline
\end{tabular}

${ }^{*} p$ value from chi square and Fishers exact tests ${ }^{*} p<0.05 ;{ }^{* *} p<0.01 ;{ }^{* * *} p<0.005$ 
Table 2 Association of chronic diseases and lifestyle factors with suicidal ideation, stratified by age

\begin{tabular}{|c|c|c|c|c|c|}
\hline \multirow[t]{2}{*}{ Characteristics } & \multicolumn{2}{|l|}{ Total } & \multirow{2}{*}{$\begin{array}{l}\text { Age } 18-30 \text { years } \\
\text { aOR }^{b}(95 \% \mathrm{Cl})\end{array}$} & \multirow{2}{*}{$\begin{array}{l}\text { Age } 31-45 \text { years } \\
\mathrm{aOR}^{\mathrm{b}}(95 \% \mathrm{Cl})\end{array}$} & \multirow{2}{*}{$\begin{array}{l}\text { Age } 46-69 \text { years } \\
\text { aOR }^{b}(95 \% \mathrm{Cl})\end{array}$} \\
\hline & cOR $(95 \% \mathrm{Cl})$ & $\mathrm{aOR}^{\mathrm{a}}(95 \% \mathrm{Cl})$ & & & \\
\hline \multicolumn{6}{|l|}{ Chronic disease } \\
\hline \multicolumn{6}{|l|}{ High blood pressure } \\
\hline Yes & $1.18(0.76-1.83)$ & $1.62(0.97-2.72)$ & $1.08(0.48-2.42)$ & $3.28(1.36-7.88)^{* *}$ & $1.22(0.54-2.75)$ \\
\hline No & 1 & 1 & 1 & 1 & 1 \\
\hline \multicolumn{6}{|l|}{ Cardiovascular disease } \\
\hline Yes & $1.74(1.01-2.98) *$ & $1.45(0.74-3.82)$ & $1.22(0.40-4.39)$ & $2.68(0.58-12.2)$ & $0.68(0.23-1.97)$ \\
\hline No & 1 & 1 & 1 & 1 & 1 \\
\hline \multicolumn{6}{|l|}{ Lifestyle factors } \\
\hline \multicolumn{6}{|l|}{ Exercise } \\
\hline No & $1.35(0.89-2.08)$ & $1.51(0.83-2.73)$ & $1.58(0.70-3.58)$ & $0.94(0.34-2.60)$ & $1.24(0.34-4.45)$ \\
\hline Yes & 1 & 1 & 1 & 1 & 1 \\
\hline \multicolumn{6}{|l|}{ Currently smoking } \\
\hline Yes & $1.56(0.86-2.82)$ & $1.39(0.58-3.36)$ & $0.92(0.25-3.32)$ & $0.92(0.09-8.79)$ & $1.75(0.39-7.77)$ \\
\hline No & 1 & 1 & 1 & 1 & 1 \\
\hline \multicolumn{6}{|l|}{ Lifetime alcohol use } \\
\hline Yes & $1.40(1.00-1.94) *$ & $1.59(0.93-2.71)$ & $1.68(0.71-3.97)$ & $2.08(0.84-5.10)$ & $1.30(0.62-2.73)$ \\
\hline No & 1 & 1 & 1 & 1 & 1 \\
\hline \multicolumn{6}{|c|}{ Sociodemographic characteristics } \\
\hline \multicolumn{6}{|c|}{ Age (years) } \\
\hline $18-30$ & $1.38(0.91-2.09)$ & $2.27(1.22-4.22) *$ & - & - & - \\
\hline $31-45$ & $1.23(0.81-1.86)$ & $1.71(0.94-3.11)$ & - & - & - \\
\hline $46-69$ & 1 & 1 & - & - & - \\
\hline \multicolumn{6}{|l|}{ Sex } \\
\hline Women & $1.84(1.28-2.66)^{* *}$ & $1.21(0.67-2.21)$ & $0.98(0.35-2.69)$ & $1.40(0.57-3.43)$ & $0.66(0.29-1.53)$ \\
\hline Men & 1 & 1 & 1 & 1 & 1 \\
\hline \multicolumn{6}{|l|}{ Marital status } \\
\hline Never married & $1.00(0.68-1.45)$ & $1.06(0.61-1.83)$ & $1.31(0.65-2.64)$ & $0.76(0.31-1.86)$ & $0.50(0.17-1.43)$ \\
\hline Separated/divorced & $1.59(0.95-2.65)$ & $1.75(0.87-3.51)$ & $2.83(1.01-7.92) *$ & $2.58(0.95-6.95)$ & $0.48(0.12-2.04)$ \\
\hline Married & 1 & 1 & 1 & 1 & 1 \\
\hline \multicolumn{6}{|l|}{ Education level } \\
\hline Primary or lower & $0.98(0.65-1.47)$ & $1.10(0.61-1.97)$ & $0.94(0.37-2.41)$ & $1.03(0.33-3.22)$ & $1.48(0.35-6.18)$ \\
\hline Secondary or lower & $1.04(0.71-1.51)$ & $1.06(0.62-1.80)$ & $0.67(0.28-1.59)$ & $1.76(0.72-4.32)$ & $1.43(0.37-5.43)$ \\
\hline High school and higher & 1 & 1 & 1 & 1 & 1 \\
\hline \multicolumn{6}{|l|}{ Employment status } \\
\hline Currently unemployed & $1.46(1.07-1.99) *$ & $1.67(0.98-2.87)$ & $1.59(0.66-3.83)$ & $2.13(0.91-4.94)$ & $1.51(0.58-3.94)$ \\
\hline Currently employed & 1 & 1 & 1 & 1 & 1 \\
\hline \multicolumn{6}{|l|}{ Place of residence } \\
\hline Urban & $1.01(0.74-1.37)$ & $0.85(0.51-1.41)$ & $0.63(0.24-1.65)$ & $1.48(0.73-3.00)$ & $0.61(0.20-1.84)$ \\
\hline Rural & 1 & 1 & 1 & 1 & 1 \\
\hline \multicolumn{6}{|l|}{ Family history of suicide } \\
\hline Yes & $1.99(1.24-3.09)^{* *}$ & $1.92(1.13-3.67)^{*}$ & $2.02(0.71-5.74)$ & $2.17(0.98-4.81)$ & $2.23(0.91-5.46)$ \\
\hline No & 1 & 1 & 1 & 1 & 1 \\
\hline \multicolumn{6}{|l|}{ Abuse factors } \\
\hline Childhood sexual abuse & & & & & \\
\hline Yes & $4.03(2.47-6.59)^{* *}$ & $2.26(1.10-4.66)^{*}$ & $3.59(1.32-9.75)^{*}$ & $1.19(0.22-6.40)$ & $1.53(0.48-4.89)$ \\
\hline No & 1 & 1 & 1 & 1 & 1 \\
\hline Adult sexual abuse & & & & & \\
\hline Yes & $3.80(2.04-7.08)^{* *}$ & $2.01(0.84-4.79)$ & $1.99(0.54-7.32)$ & $2.08(0.56-7.73)$ & $3.02(0.96-9.40)$ \\
\hline
\end{tabular}


Table 2 (continued)

\begin{tabular}{|c|c|c|c|c|c|}
\hline \multirow[t]{2}{*}{ Characteristics } & \multicolumn{2}{|l|}{ Total } & \multirow{2}{*}{$\begin{array}{l}\text { Age } 18-30 \text { years } \\
\text { aOR }^{b}(95 \% \mathrm{Cl})\end{array}$} & \multirow{2}{*}{$\begin{array}{l}\text { Age } 31-45 \text { years } \\
\text { aOR }^{b}(95 \% \mathrm{Cl})\end{array}$} & \multirow{2}{*}{$\begin{array}{l}\text { Age } 46-69 \text { year } \\
\mathrm{aOR}^{\mathrm{b}}(95 \% \mathrm{Cl})\end{array}$} \\
\hline & COR $(95 \% \mathrm{Cl})$ & $\mathrm{aOR}^{\mathrm{a}}(95 \% \mathrm{Cl})$ & & & \\
\hline No & 1 & 1 & 1 & 1 & 1 \\
\hline \multicolumn{6}{|l|}{ Threats } \\
\hline Yes & $2.36(1.64-3.39)^{* *}$ & $1.88(1.15-3.06)^{*}$ & $1.69(0.73-3.90)$ & $1.83(0.77-4.33)$ & $1.90(0.78-4.66)$ \\
\hline No & 1 & 1 & 1 & 1 & 1 \\
\hline
\end{tabular}

cOR, crude odds ratio; aOR, adjusted odds ratio; $\mathrm{Cl}$, confidence interval

${ }^{*} p<0.05$; ${ }^{* *} p<0.01$; ${ }^{* * *} p<0.005$

a Adjusted for all other listed variables in the model

b Adjusted for all other listed variables in the model, excluding age

Lack of exercise [42-44] and use of alcohol [21, 45] are established risk factors associated with suicidal ideation. Consistent with these findings, our study indicated that not exercising and lifetime alcohol use were associated with past-year suicidal ideation among the currently employed population. The relationship between alcohol use and suicidal ideation identified in this study accords with evidence from other developing [25, 46, 47] and developed $[48,49]$ countries. When people experience stressful life events that in turn result in suicidal ideation [50], they may use alcohol as a coping mechanism [51]. However, given our cross-sectional design, we limited our study to association rather than causal pathways. Furthermore, currently employed individuals, particularly those doing stressful jobs, are prone to drinking alcohol [52] and not exercising because they are stressed and busy due to work [53]. Nevertheless, we determined that currently employed individuals constitute a high-risk group for suicidal ideation, which is a novel finding in the context of SSA.

Our study demonstrated that HBP was associated with past-year suicidal ideation among currently employed individuals probably because of pressure at work $[50,54]$ or work dissatisfaction [55], which may impair an individual's ability to cope, resulting in suicidal ideation. The findings are congruent with those in the literature [56]; however, the identification of currently employed individuals as a high-risk group for past-year suicidal ideation is unique.

Our findings are consistent with those of studies reporting that young age is associated with suicidal ideation [38, 57-59]. Most mental health problems, including suicidal ideation, occur among people in adolescence and are likely to persist through adulthood if not appropriately resolved $[29,60]$. Moreover, the association of family history of suicide with past-year suicidal ideation was significant $(p<0.05)$ among individuals aged $31-45$ years and currently unemployed individuals. The confluence of these factors can be explained in light of the premise that middle adulthood is the prime time of productivity in human development [61], and additional stressors increase the burden [62], which may influence suicidal ideation. In addition, current unemployment is considered a form of defeat, and a history of family suicide can exacerbate the burden, resulting in suicidal ideation [63]. Our study findings are consistent with those of studies conducted in other countries, which have reported that a family history of suicide is associated with suicidal ideation $[8,64,65]$.

We demonstrated that, compared with being married, being separated or divorced was associated with pastyear suicidal ideation, particularly among the young population. Our findings agree with those of a South Korea study; however, that study focused on comparing suicidal ideation between those with and without major depression [66]. Additionally, our data revealed a significant association of childhood sexual abuse among individuals aged 18-30 years and who were currently unemployed with past-year suicidal ideation. Such a relationship may develop because of the joint factors of accumulated negative childhood experiences [67] and being currently unemployed [68], which impair the ability of young adults to cope [69].

\section{Strengths and limitations}

Our study used a large sample from a nationally representative survey that employed the WHO-recommended approach for assessing noncommunicable disease risk factors. The survey instruments were validated, and the country-level surveyors or data collection team members were well trained, yielding satisfactory quality control; moreover, the response rate was good. Such a robust survey methodology lends credibility to our findings. Moreover, because the present study employed a complex design to account for design, clustering, and sample weights, the results are generalizable to the Eswatini population. In general, we furnished novel findings (in the Eswatini context) on the association of HBP, physical 
Table 3 Association of chronic diseases and lifestyle factors with suicidal ideation, stratified by employment status

\begin{tabular}{|c|c|c|}
\hline Characteristics & $\begin{array}{l}\text { Currently Employed } \\
\operatorname{aOR}^{\mathrm{a}}(95 \% \mathrm{CI})\end{array}$ & $\begin{array}{l}\text { Currently Unemployed } \\
\mathrm{aOR}^{\mathrm{a}}(95 \% \mathrm{Cl})\end{array}$ \\
\hline \multicolumn{3}{|l|}{ Chronic diseases } \\
\hline \multicolumn{3}{|l|}{ High blood pressure } \\
\hline Yes & $3.38(1.54-7.40)^{* *}$ & $0.87(0.47-1.58)$ \\
\hline No & 1 & 1 \\
\hline \multicolumn{3}{|l|}{ Cardiovascular disease } \\
\hline Yes & $1.52(0.57-4.06)$ & $0.99(0.41-2.41)$ \\
\hline No & 1 & 1 \\
\hline \multicolumn{3}{|l|}{ Lifestyle factors } \\
\hline \multicolumn{3}{|l|}{ Exercise } \\
\hline No & $2.65(1.09-6.39)^{*}$ & $1.15(0.55-2.40)$ \\
\hline Yes & 1 & 1 \\
\hline \multicolumn{3}{|l|}{ Currently smoking } \\
\hline Yes & $1.57(0.37-6.60)$ & $1.58(0.46-5.38)$ \\
\hline No & 1 & 1 \\
\hline \multicolumn{3}{|l|}{ Lifetime alcohol use } \\
\hline Yes & $2.40(1.14-5.05)^{*}$ & $1.62(0.86-3.08)$ \\
\hline No & 1 & 1 \\
\hline \multicolumn{3}{|l|}{ Demographics } \\
\hline \multicolumn{3}{|l|}{ Age (years) } \\
\hline $18-30$ & $3.50(1.01-12.1)^{*}$ & $1.93(0.10-0.86)$ \\
\hline $31-45$ & $2.15(0.72-6.42)$ & $1.78(0.72-6.42)$ \\
\hline $46-69$ & 1 & 1 \\
\hline \multicolumn{3}{|l|}{ Sex } \\
\hline Women & $2.36(0.93-5.99)$ & $0.93(0.39-5.99)$ \\
\hline Men & 1 & 1 \\
\hline \multicolumn{3}{|l|}{ Marital status } \\
\hline Never married & $0.97(0.43-2.21)$ & $1.54(0.82-2.88)$ \\
\hline Separated/divorced & $1.40(0.40-4.92)$ & $2.21(0.91-5.34)$ \\
\hline Married & 1 & 1 \\
\hline \multicolumn{3}{|l|}{ Education level } \\
\hline Primary or lower & $1.33(0.49-3.63)$ & $0.83(0.39-1.78)$ \\
\hline Secondary or lower & $1.49(0.71-3.13)$ & $0.80(0.39-1.63)$ \\
\hline High school and higher & 1 & 1 \\
\hline \multicolumn{3}{|l|}{ Place of residence } \\
\hline Urban & $0.81(0.43-1.53)$ & $0.89(0.49-1.63)$ \\
\hline Rural & 1 & 1 \\
\hline \multicolumn{3}{|l|}{ Family history of suicide } \\
\hline No & $1.43(0.65-3.11)$ & $2.42(1.07-5.45)^{*}$ \\
\hline Yes & 1 & 1 \\
\hline \multicolumn{3}{|l|}{ Abuse factors } \\
\hline \multicolumn{3}{|l|}{ Childhood sexual abuse } \\
\hline Yes & $2.37(0.66-8.55)$ & $2.58(1.24-5.38)^{*}$ \\
\hline No & 1 & 1 \\
\hline \multicolumn{3}{|l|}{ Adult sexual abuse } \\
\hline Yes & $0.53(0.13-2.09)$ & $4.94(1.94-12.5)^{* *}$ \\
\hline No & 1 & 1 \\
\hline \multicolumn{3}{|l|}{ Threats } \\
\hline Yes & $2.37(1.01-5.53)^{*}$ & $1.61(0.77-3.38)$ \\
\hline No & 1 & 1 \\
\hline
\end{tabular}

aOR, adjusted odds ratio; $\mathrm{Cl}$, confidence interval

${ }^{*} p<0.05 ;{ }^{* *} p<0.01 ;{ }^{* * *} p<0.005$

${ }^{\text {a }}$ Adjusted for all other listed variables in the model 
exercise, and lifetime alcohol use with past-year suicidal ideation.

Our study entailed secondary analysis and a crosssectional design in which the survey questions used to generate data were imprecise; therefore, our results must be interpreted with caution and be understood to reflect associations, not causation. However, survey questions have been used similarly in the literature to measure the same concepts by using single items [20, 70, 71]. Furthermore, to assess SES, it was estimated using household income. However, the data set contained many missing data points $(67.2 \%)$ and was therefore omitted in the analysis; nevertheless, we incorporated education level [72] and employment status as proxies [73]. The measurement of lifestyle factors was not specific enough to yield good data; for example, the frequency and intensity of exercise were unclear, which may have led to exposure underestimation. Moreover, suicidal ideation related questions were not specific enough to properly classify those with and without suicidal ideation because responses were subject to various interpretations by the respondents. Data on all variables, including suicidal thoughts, HBP, and smoking history, were self-reported, which may be subject to recall bias. Furthermore, respondents may furnish socially acceptable but inaccurate answers, particularly for questions on chronic diseases, lifestyle factors, and suicidal thoughts, for fear of being judged.

Our study has some critical implications that can guide strategic policy decisions. Eswatini lacks a suicide prevention policy and has no priority indicators of suicidal behaviors in client management information systems (CMISs) [74]. Therefore, the development and integration of such indicators into CMISs is necessary. In brief, a CMIS is a surveillance database system that is under the custody of the health ministry in Eswatini, and data are deidentified and stored in servers. Although debates are ongoing regarding surveillance and records of mental health and health behaviors, they are in line with the WHO mental health action plan $[9,75]$. Although the integration of suicidal behavior and other lifestyle indicators is advocated, it raises ethical concerns, which must be considered [76].

Physical exercise should be promoted among currently employed individuals to improve their health. Consistent with previous studies, our study demonstrated that lifetime alcohol use is associated with past-year suicidal ideation among the currently employed population [47]. Our findings can form the basis for the design and implementation of suicidal ideation prevention or intervention programs, particularly for the high-risk groups identified. Furthermore, the implementation and integration of suicidal behavior indicators to monitoring and evaluation systems could enhance the identification and characterization of high-risk groups (e.g., those aged 31-45 years and those who are unemployed, as identified in our study) for suicidal behavior [77].

\section{Conclusions and recommendations}

Our findings indicated that HBP, lack of exercise, and lifetime alcohol use among currently employed individuals were associated with past-year suicidal ideation. Our study results form the basis for a call to action for better survey research in Eswatini (by using more validated scales than a single item); moreover, adopting longitudinal cohort designs will allow the establishment of causality in suicidal behavior studies. Furthermore, we advocate for mental health surveys to understand the mechanisms underlying this association among different employment codes. Studies should consider more comorbid conditions, such as other common mental health issues (e.g., depression) and chronic diseases (e.g., human immunodeficiency virus), and include general health information.

\section{Acknowledgements \\ We are grateful to all Eswatini citizens who participated in the study.}

\section{Authors' contributions}

Yi-Hua Chen and Mfundi PS Motsa designed the study; Hung-Yi Chiou, Yi-Hua Chen, and Mfundi PS Motsa analyzed and interpreted the results; Mfundi PS Motsa and Yi-Hua Chen conducted the literature review and drafted the final manuscript; and all authors contributed to and approved the final manuscript. Ethical declarations:

\section{Funding}

No funding was received for this study.

Author Information.

PhD Program in Global Health and Health Security, College of Public Health,

Taipei Medical University, Taipei, Taiwan.

Mfundi President Sebenele Motsa.

School of Public Health, College of Public Health, Taipei Medical University, Taipei, Taiwan.

Hung-Yi Chiou and Yi-Hua Chen.

\section{Availability of data and materials}

The datasets used or analyzed were with permission from the WHO NCD Microdata Repository, which serves as custodian of publicly available data; data are available on the website https://extranet.who.int/ncdsmicrodata/ index.php/catalog.

\section{Declarations}

Ethics approval and consent to participate

The approval for data collection from the STEPS was provided by the Swaziland Ethics Committee, renamed the National Health Research Review Board. All interviewed participants provided informed consent to participate in the 2013-2014 STEPS and to publish information obtained during the survey. Data used in this analysis were anonymous, with no individual names and identifiable information for participants.

Consent for publication

Not applicable. 


\section{Competing interests}

The authors declare that they have no known competing financial interests or personal relationships that could influence the work reported in this paper.

\section{Author details}

1PhD Program in Global Health and Health Security, College of Public Health, Taipei Medical University, 250 Wuxing St., Taipei City 110, Taiwan. ${ }^{2}$ School of Public Health, College of Public Health, Taipei Medical University, 250 Wuxing St., Taipei City 110, Taiwan. ${ }^{3}$ Institute of Population Health Sciences, National Health Research Institutes, Zhunan Town, Miaoli County 35053, Taiwan.

Received: 14 May 2021 Accepted: 11 November 2021

\section{Published online: 10 December 2021}

\section{References}

1. Naghavi M. Global, regional, and national burden of suicide mortality 1990 to 2016: systematic analysis for the Global Burden of Disease Study 2016. BMJ. 2019;364.

2. Organization WH. Suicide Key Information.Fact Sheet. 2019. https://www. who.int/news-room/fact-sheets/detail/suicide. Accessed 8 September 2020.

3. Boduszek D, Debowska A, Ochen EA, Fray C, Nanfuka EK, Powell-Booth K, et al. Prevalence and correlates of non-suicidal self-injury, suicidal ideation, and suicide attempt among children and adolescents: Findings from Uganda and Jamaica. 2021;283:172-8.

4. Organization WH. Preventing suicide: A global imperative: World Health Organization; 2014. https://www.who.int/publications/i/item/97892 41564779. Accessed 18 Aug 2021.

5. House A, Kapur N, Knipe D. Thinking about suicidal thinking. Lancet Psychiatry. 2020;7(11):997-1000.

6. Klonsky ED, May AM, Saffer BY. Suicide, suicide attempts, and suicidal ideation. Annual review of clinical psychology. 2016;12.

7. Nock MK, Borges G, Bromet EJ, Alonso J, Angermeyer M, Beautrais A, et al. Cross-national prevalence and risk factors for suicidal ideation, plans and attempts. Brit J Psychiatry. 2008;192(2):98-105.

8. Jordans M, Rathod S, Fekadu A, Medhin G, Kigozi F, Kohrt B, et al. Suicidal ideation and behaviour among community and health care seeking populations in five low-and middle-income countries: a cross-sectional study. Epidemiol Psychiatric Sci. 2018;27(4):393.

9. Organization WH. mhGAP intervention guide for mental, neurological and substance use disorders in non-specialized health settings: mental health Gap Action Programme ("mhGAP)F-version 2.0. 2016. 2016. https://www. who.int/publications/i/item/9789241549790. Accessed 17 August 2021.

10. Cabello M, Miret M, Ayuso-Mateos JL, Caballero FF, Chatterji S, TobiaszAdamczyk B, et al. Cross-national prevalence and factors associated with suicide ideation and attempts in older and young-and-middle age people. Aging Mental Health. 2020;24(9):1533-42.

11. Mars B, Burrows S, Hjelmeland H, Gunnell D. Suicidal behaviour across the African continent: a review of the literature. BMC Public Health. 2014;14(1):1-14.

12. Bachmann SJljoer, health p. Epidemiology of suicide and the psychiatric perspective. 2018;15(7):1425.

13. Bantjes J, lemmi V, Coast E, Channer K, Leone T, McDaid D, et al. Poverty and suicide research in low-and middle-income countries: systematic mapping of literature published in English and a proposed research agenda. 2016;3.

14. lemmi V, Bantjes J, Coast E, Channer K, Leone T, McDaid D, et al. Suicide and poverty in low-income and middle-income countries: a systematic review. 2016;3(8):774-83.

15. Lapierre S, Desjardins S, Préville M, Berbiche D, Lyson Marcoux M. Wish to die and physical illness in older adults. Psychology. 2015;5(2):125-37.

16. Scott KM, Hwang I, Chiu W-T, Kessler RC, Sampson NA, Angermeyer M, et al. Chronic physical conditions and their association with first onset of suicidal behavior in the world mental health surveys. Psychosomatic Medicine. 2010;72(7):712-9.

17. Chan H-L, Liu C-Y, Chau Y-L, Chang C-M. Prevalence and association of suicide ideation among Taiwanese elderly-a population-based crosssectional study. Chang Gung Med J. 2011;34(2):197-204.
18. Kye S-Y, Park K. Suicidal ideation and suicidal attempts among adults with chronic diseases: a cross-sectional study. Comprehensive psychiatry. 2017;73:160-7.

19. Tsegay A, Damte A, Kiros A. Determinants of suicidal ideation among patients with mental disorders visiting psychiatry outpatient unit in Mekelle town, psychiatric clinics, Tigray, Northern Ethiopia: a case-control study. Ann General Psychiatry. 2020;19(1):1-12.

20. Pengpid S, Peltzer KJljomhs. Prevalence and correlates of suicidal behaviour among adults in Malawi: a nationally representative cross-sectional survey in 2017. 2021;15(1):1-8.

21. Fekadu A, Medhin G, Selamu M, Shiferaw T, Hailemariam M, Rathod SD, et al. Non-fatal suicidal behaviour in rural Ethiopia: a cross-sectional facility-and population-based study. 2016;16(1):1-9.

22. Andoh-Arthur J, Hjelmeland H, Osafo J, Knizek BLJCP. Substance use and suicide among men in Ghana: A qualitative study. 2020:1-13.

23. Nie J, O'Neil A, Liao B, Lu C, Aune D, Wang YJJoad. Risk factors for completed suicide in the general population: A prospective cohort study of 242, 952 people. $2021 ; 282: 707-11$

24. Vancampfort D, Hallgren M, Firth J, Rosenbaum S, Schuch FB, Mugisha J, et al. Physical activity and suicidal ideation: A systematic review and meta-analysis. 2018;225:438-48.

25. Goldstone D, Bantjes J, Nel D, Stanbridge J, Lewis I. Alcohol use predicts emergency psychiatric unit admission for non-fatal suicidal behaviour in the Western Cape (South Africa): a case-control study. Int J Psychiatry Clin Practice. 2020;24(2):163-72.

26. Organization WH. Global Health Observatory Data Repository. [Suicide rate estimates by country] 2016. 2016. https://apps.who.int/gho/data/ node.main.MHSUICIDE. Accessed 17 August 2021.

27. Almansour AM, Siziya S. Suicidal ideation and associated factors among school going adolescents in Swaziland. Afr Health Sci. 2017;17(4):1172-7.

28. Pengpid S, Peltzer K. The Prevalence and Correlates of Suicidal Ideation, Plans and Suicide Attempts among 15-to 69-Year-Old Persons in Eswatini. Behavioral Sciences. 2020;10(11):172.

29. McGrath JJ, Saha S, Al-Hamzawi AO, Alonso J, Andrade L, Borges G, et al. Age of onset and lifetime projected risk of psychotic experiences: cross-national data from the World Mental Health Survey. Schizophrenia Bulletin. 2016:42(4):933-41.

30. Organization WH. Noncommunicable diseases country profiles 2018. 2018. https://www.who.int/publications/i/item/ncd-country-profiles2018. Accessed 17 August 2021.

31. Organization WH. NCD Micro Data Repository. 2020. https://extranet.who. int/ncdsmicrodata/index.php/access_licensed/track/694. Accessed 13 August 2020.

32. Eswatini Government MOH. WHO STEPS Survey on Non-CommunnicableDisease Risk Factor Surveillence Report. 2015. https://www.who.int/ ncds/surveillance/steps/Swaziland_2014_STEPS_Report.pdf. Accessed 13 August 2020

33. Stansfeld SA, Clark C, Smuk M, Power C, Davidson T, Rodgers B. Childhood adversity and midlife suicidal ideation. Psychol Med. 2017:47(2):327-40.

34. Dendup T, Zhao Y, Dorji T, Phuntsho S. Risk factors associated with suicidal ideation and suicide attempts in Bhutan: An analysis of the 2014 Bhutan STEPS Survey data. PLoS one. 2020;15(1):e0225888.

35. Moazzami K, Dolmatova EV, Feurdean M. Suicidal ideation among adults with cardiovascular disease: The National Health and Nutrition Examination Survey. General Hospital Psychiatry. 2018;51:5-9.

36. Lee H, Myung W, Kim SE, Kim DK, Kim H. Ambient air pollution and completed suicide in 26 South Korean cities: Effect modification by demographic and socioeconomic factors. Sci Total Environ. 2018;639:944-51.

37. Bifftu BB, Tiruneh BT, Dachew BA, Guracho YD. Prevalence of suicidal ideation and attempted suicide in the general population of Ethiopia: a systematic review and meta-analysis. Int J Mental Health Systems. 2021:15(1):1-12.

38. Jordans M, Rathod S, Fekadu A, Medhin G, Kigozi F, Kohrt B, et al. Suicidal ideation and behaviour among community and health care seeking populations in five low-and middle-income countries: a cross-sectional study. 2018;27(4):393-402.

39. Adewuya AO, Ola BA, Coker OA, Atilola O, Zachariah MP, Olugbile O, et al. Prevalence and associated factors for suicidal ideation in the Lagos State Mental Health Survey, Nigeria. 2016;2(6):385-9. 
40. Muruthi JR, Spafford SG, Osa ML, DeLouize A, Kowal P, Biritwum $R$, et al. Suicidal ideation in older Ghanaian women: The roles of bodily pain, functional limitation, and chronic health conditions. 2021:0020764021991179.

41. Lehmann M, Kohlmann S, Gierk B, Murray AM, Löwe B. Suicidal ideation in patients with coronary heart disease and hypertension: Baseline results from the DEPSCREEN-INFO clinical trial. Clin Psychol Psychother. 2018;25(6):754-64.

42. Vancampfort D, Hallgren M, Firth J, Rosenbaum S, Schuch FB, Mugisha J, et al. Physical activity and suicidal ideation: A systematic review and meta-analysis. J Affective Disorders. 2018;225:438-48.

43. Uddin R, Burton NW, Maple M, Khan SR, Tremblay MS, Khan A. Low physical activity and high sedentary behaviour are associated with adolescents' suicidal vulnerability: Evidence from 52 low-and middle-income countries. Acta Paediatrica. 2020;109(6):1252-9.

44. Grasdalsmoen M, Eriksen HR, Lønning KJ, Sivertsen BJBp. Physical exercise, mental health problems, and suicide attempts in university students. 2020;20(1):1-11.

45. Breet E, Goldstone D, Bantjes JJBph. Substance use and suicidal ideation and behaviour in low-and middle-income countries: a systematic review. 2018;18(1):1-18.

46. Abdu Z, Hajure M, Desalegn DJPr, management b. Suicidal behavior and associated factors among students in Mettu University, South West Ethiopia, 2019: an institutional based cross-sectional study. 2020;13:233.

47. Breet E, Goldstone D, Bantjes J. Substance use and suicidal ideation and behaviour in low-and middle-income countries: a systematic review. BMC Public Health. 2018;18(1):1-18.

48. Nichter B, Stein MB, Norman SB, Hill ML, Straus E, Haller M, et al. Prevalence, Correlates, and Treatment of Suicidal Behavior in US Military Veterans: Results From the 2019-2020 National Health and Resilience in Veterans Study. 2021:82(5):0.

49. Robert HPJJCP. Prevalence, Correlates, and Treatment of Suicidal Behavior in US Military Veterans. 2021:82(5):20m13714.

50. Loerbroks A, Cho S-I, Dollard MF, Zou J, Fischer JE, Jiang Y, et al. Associations between work stress and suicidal ideation: Individual-participant data from six cross-sectional studies. 2016;90:62-9.

51. Norström T, Rossow IJAOSR. Alcohol consumption as a risk factor for suicidal behavior: a systematic review of associations at the individual and at the population level. 2016;20(4):489-506.

52. Obeid S, Akel M, Haddad C, Fares K, Sacre H, Salameh P, et al. Factors associated with alcohol use disorder: the role of depression, anxiety, stress, alexithymia and work fatigue-a population study in Lebanon. 2020;20(1):1-11.

53. Han B, Crosby AE, Ortega LA, Parks SE, Compton WM, Gfroerer JJCp. Suicidal ideation, suicide attempt, and occupations among employed adults aged 18-64 years in the United States. 2016;66:176-86.

54. Belete H, Ergetie T, Ali T, Birhanu S, Belete TJPR, Management B. WorkRelated Stress and Associated Factors Among Textile Factory Employees in Northwest Ethiopia: A Cross-Sectional Study. 2020;13:1071.

55. Virtanen M, Nyberg ST, Batty GD, Jokela M, Heikkilä K, Fransson El, et al. Perceived job insecurity as a risk factor for incident coronary heart disease: Systematic Review Meta-Analysis. 2013;347.

56. Benson C, Singer D, Carpinella CM, Shawi M, Alphs L. The Health-Related Quality of Life, Work Productivity, Healthcare Resource Utilization, and Economic Burden Associated with Levels of Suicidal Ideation Among Patients Self-Reporting Moderately Severe or Severe Major Depressive Disorder in a National Survey. Neuropsychiatric Dis Treatment. 2021;17:111.

57. Jo A, Jeon $\mathrm{M}, \mathrm{Oh} \mathrm{H}$. Age-differentiated risk factors of suicidal ideation among young and middle-aged Korean adults. Osong Public Health Research Perspectives. 2017;8(3):201.

58. Stoliker BE, Verdun-Jones SN, Vaughan AD. The relationship between age and suicidal thoughts and attempted suicide among prisoners. Health Justice. 2020;8(1):1-19.

59. Sinyor M, Tse R, Pirkis JJCoip. Global trends in suicide epidemiology. 2017:30(1):1-6.

60. Organization WH. Child Mental Health Atlas.Geneva,Switzerland:WHO. 2005. https://www.who.int/mental_health/resources/Child_ado_atlas. pdf. Accessed 17 March 2021.

61. Maree JGJECD, Care. Promoting career development and life design in the early years of a person's life. 2018;188(4):425-36.
62. Roeder KM, Cole DAJS, Behavior LT. Simultaneous longitudinal examination of hopelessness, thwarted belongingness, and perceived burdensomeness as predictors of suicide ideation. 2019:49(4):1058-71.

63. O'Connor RC, Kirtley OJ. The integrated motivational-volitional model of suicidal behaviour. Philosophical Trans Royal Soc B: Biol Sci. 2018;373(1754):20170268

64. Rajalin M, Hirvikoski T, Renberg ES, Åsberg M, Jokinen J. Family history of suicide and interpersonal functioning in suicide attempters. Psychiatry Res. 2017:247:310-4.

65. Borges G, Nock MK, Abad JMH, Hwang I, Sampson NA, Alonso J, et al. Twelve-month prevalence of and risk factors for suicide attempts in the World Health Organization World Mental Health Surveys. 2010;71(12):0-

66. Omary A. Predictors and confounders of suicidal ideation and suicide attempts among adults with and without depression. Psychiatric Quarterly. 2020:1-15.

67. Cluver L, Orkin M, Boyes ME, Sherr LJJoAH. Child and adolescent suicide attempts, suicidal behavior, and adverse childhood experiences in South Africa: a prospective study. 2015;57(1):52-9.

68. Onah MN, Field S, Bantjes J, Honikman SJAowsmh. Perinatal suicidal ideation and behaviour: psychiatry and adversity. 2017;20(2):321-31.

69. Bertule M, S.B. Sebre, and A. Kolesovs. Childhood abuse experiences, depression and dissociation symptoms in relation to suicide attempts and suicidal ideation. J Trauma Dissociation. 2021:1-17.

70. Quarshie EN-B, Onyeaka HK, Asante KOJBp. Suicidal behaviours among adolescents in Liberia. 2020;20(1):1-12.

71. Adewuya AO, Oladipo EOJEc, psychiatry a. Prevalence and associated factors for suicidal behaviours (ideation, planning, and attempt) among high school adolescents in Lagos, Nigeria. 2020;29(11):1503-12.

72. Kim OY, et al. Selected food consumption mediates the association between education level and metabolic syndrome in Korean adults. Ann Nutri Metab. 2017:70(2):122-31.

73. Verma SaAM. Depression, anxiety, and stress and socio-demographic correlates among general Indian public during COVID-19. Int J Soc Psychiatry. 2020;66(8):756-62.

74. Millar E, Silvestre E, Davis H, Wood F. Implementing Swaziland's Client Management Information System: Stakeholders'Views of the Process and Recommendations to Improve It. 2019.

75. Organization WH. National suicide prevention strategies: Progress, examples and indicators. 2018. https://www.who.int/publications/i/item/natio nal-suicide-prevention-strategies-progress-examples-and-indicators. Accessed 17 March 2021.

76. Lee LMJTOHoPHE. Public health surveillance: Ethical considerations. 2019:320.

77. Kisa AaS-HC. Global, regional, and national burden of suicide mortality 1990 to 2016: systematic analysis for the Global Burden of Disease Study 2016. the BMJ. 2019;364(194).

\section{Publisher's Note}

Springer Nature remains neutral with regard to jurisdictional claims in published maps and institutional affiliations. 